\title{
DESENVOLVIMENTO, O VERDADEIRO NOME DA PAZ
}

\author{
D. Manuel da Rocha Felício*
}

\begin{abstract}
$O$ artigo pretende demonstrar como o desenvolvimento económico, sendo, embora, importante para a paz dos povos, não é uma condição suficiente. E, como tal, se a paz não se reduz à ausência de guerra, também o desenvolvimento capaz de gerar a paz verdadeira está longe de se identificar apenas com a sua vertente material.
\end{abstract}

Palavras-chaves: crescimento económico, desenvolvimento, desenvolvimento humano, paz, harmonia.

\section{INTRODUÇÃO}

O peso social e político de um país mede-se vulgarmente pelos níveis do seu desenvolvimento ou crescimento económico. A divisão entre os países existentes no mundo fazia-se, não há muitas décadas atrás, classificando-os entre países desenvolvidos e países subdesenvolvidos, estes ultimamente classificados como países em vias de desenvolvimento. Por estas e outras verificações, depreendemos que o desenvolvimento ou crescimento continua a ser a referência principal para determinar a importância de um país ou mesmo de um conjunto de países no concerto das relações multilaterais de nível internacional.

Impõe-se agora determinar qual é o desenvolvimento que realmente conta e que interessa contabilizar para a cota de valor a atribuir a uma sociedade concreta. Desde já adiantamos que este desenvolvimento não pode identificar-se pura e simplesmente com o desenvolvimento económico. Ele tem de incluir todas as outras dimensões de que é feito o ser humano na plenitude das suas vivências e potencialidades. A elas nos vamos referir mais à frente.

\footnotetext{
Bispo da Guarda
} 
Ao admitirmos que o desenvolvimento económico não é tudo e que as relações sociais e económicas também são parte do desenvolvimento, por um lado sublinhamos o peso que nele tem o factor humano. Não pode, de facto, haver desenvolvimento à custa das pessoas, sejam elas todas ou apenas algumas. Por outro lado, tocamos também o ponto nevrálgico da relação estruturante que existe entre o desenvolvimento e a paz. A paz, de facto, não pode ser entendida como simples ausência de guerra, mas sim como equilíbrio na relação comprometida das pessoas entre si com vista a objectivos de bem para todos. Só pode haver paz onde houver respeito, defesa e promoção do Bem Comum, ou seja quando todos se sentirem respeitados nos seus direitos e valorizados nas suas competências como verdadeiros actores da história.

\section{O DESENVOLVIMENTO QUE GERA A PAZ}

\section{a) $\mathrm{O}$ desenvolvimento económico não é suficiente.}

O simples desenvolvimento económico, por si só, não gera a paz; paz que é hoje, mais do que nunca, factor decisivo para o bem estar pessoal e social das populações. E não precisamos de aduzir muitos argumentos para provar esta tese, porque os factos da vida social e política, na actualidade das nações, o demonstram à sociedade.

Em consequência desta constatação, podemos concluir que o verdadeiro desenvolvimento, no fundo procurado pelas pessoas, é uma realidade global e não apenas sectorial, onde estão envolvidos os aspectos económicos, mas onde os mais decisivos são outros, como os culturais, os sociais, os que fazem de cada ser humano um verdadeiro criador e não apenas consumidor, um verdadeiro actor social e não apenas executor de ordens que lhe vêm de fora. O verdadeiro desenvolvimento conduz cada ser humano para a descoberta e valorização da sua interioridade mais profunda. Implica dar peso à relação interpessoal e ao comprometimento com os outros não só para realizar projectos de crescimento com impacto na realidade social, mas também porque cada pessoa só cresce e só se realiza na medida em que alarga e aprofunda a sua rede de relações.

O pleno desenvolvimento supõe, por isso, uma visão global do homem e da humanidade. Por sua vez, esta visão global do homem e da humanidade envolve o reconhecimento de que o mesmo homem é, de facto, o fundamento, o eixo e o fim de todo o desenvolvimento, a começar pelo desenvolvimento económico. 


\section{b) $\mathbf{O}$ homem, medida do desenvolvimento}

Se o homem é, como acabámos de referir, o fundamento, o eixo e o fim de todo o desenvolvimento, então este tem de aceitar ser medido e autorizado pelo ser humano na totalidade das suas dimensões. Aquilo que for o ser humano na totalidade das suas dimensões e valências há-de ser também o desenvolvimento. Para avaliarmos qualquer expressão de desenvolvimento, temos de levar sempre muito a sério o princípio que podemos enunciar assim: a única realidade que verdadeiramente conta no mundo é o homem, cada homem, cada grupo de homens, até chegar à humanidade inteira (Cfr. PAPA PAULO VI - Encíclica "Populorum Progressio", Março de 1967, n 14).

Ora, o ser humano tem de entender-se, antes de mais e por um lado, como realidade diferente do que é pura e simplesmente material ou mundano; por outro lado diferente do puro e simplesmente espiritual. De facto, não somos anjos, mas também não somos redutíveis a puras manifestações da matéria. Então o que somos?

O ser humano é, sem dúvida, uma realidade corpórea, material, mas estruturalmente aberta à relação com o outro pela sua intersubjectividade; à relação com o mundo pela tendência a conhecê-lo e a dominá-lo para o colocar ao seu serviço; à relação consigo mesmo na sua intimidade mais profunda e finalmente à relação com o totalmente outro, que é Deus, origem e fim de toda a existência.

É mergulhando na profundidade de si mesmo, decidindo sobre a sua pessoa, no santuário mais íntimo da sua consciência e aí fazendo muitas opções com repercussão na realidade mundana circundante que o homem se sente mesmo dono do seu destino e do mundo. Ele de facto foi criado para ser senhor e não escravo; senhor do mundo e da história, definindo para ela um rumo, que, todavia, nunca pode estar em contradição com a natureza das pessoas e das coisas. Quando surge essa contradição, estamos perante o mau uso da liberdade humana, que atraiçoa a consciência da pessoa, sempre a fonte e a referência aferidora do comportamento pessoal e social por onde passa todo o desenvolvimento.

Ao tomar consciência da sua identidade, o ser humano sente-se alguém enraizado na matéria e na história, mas também se sente vocacionado para transcender a mesma matéria e a mesma história, portanto portador de uma abertura existencial e estruturante para 0 mundo, para os outros e para Deus. Portanto, todo o desenvolvimento que se queira prezar de ser autêntico desenvolvimento, tem de aceitar o juízo permanente deste confronto com o homem todo na pluralidade das suas dimensões. Basta que alguma delas não seja contemplada para não termos o desejado desenvolvimento completo ou integral. 


\section{c) A dialéctica do ser e do ter na pessoa humana, instância crítica do verdadeiro desenvolvimento.}

$\mathrm{Na}$ pessoa humana o ser e o ter são dimensões em constante relação dialéctica ou seja nenhuma delas pode eliminar a outra, mas o ter tem de colocar-se sempre ao serviço do ser. É legítimo o desejo de ter o necessário e trabalhar para obter esse necessário é um dever. Todavia também é preciso que cada ser humano esteja sempre de sobreaviso contra a cobiça ou seja contra a tendência para fazer do ter e do poder que lhe é inerente a medida da sua realização pessoal. Diz a encíclica "Populorum Progressio" que já citámos acima, o seguinte: "Tanto para os povos como para as pessoas possuir mais não é o fim último" $\left(n^{\circ} 19\right)$. Possuir o necessário é sim a condição para que cada ser humano cumpra verdadeiramente a sua interioridade, se projecte na relação gratuita e generosa com os outros, aprofunde os conhecimentos do mundo e a utilização razoável que dele há-de fazer para bem de todos. Possuir o indispensável é também necessário para cada um construir o seu próprio projecto de vida e responsavelmente o assumir no teatro do mundo e sempre aberto às dimensões do infinito.

\section{A PAZ QUE NASCE DO DESENVOLVIMENTO}

Desenvolvimento, o novo nome da paz é o título da conclusão da encíclica "Populorum Progressio", onde se diz: "A paz não se reduz a uma ausência de guerra, fruto do equilíbrio sempre precário das forças. Constrói-se dia a dia, na busca da ordem querida por Deus, que traz consigo uma justiça mais perfeita entre os homens" ( ${ }^{\circ} 76$, que cita, por sua vez o n 78 da "Gaudium et Spes" do Concílio Vaticano II).

Esta passagem da "Populorum Progressio" sublinha que a paz é, por si mesma, uma atitude positiva e não apenas negativa ou de recusa nem que seja só dos malefícios da guerra. Enquanto atitude positiva, a paz é compromisso de cada pessoa na procura da ordem querida pelo próprio criador, da qual faz parte a justiça. Porém, no progresso de construir a paz, a paixão pela justiça, entendida como reconhecimento dos direitos de todos e de cada um, pode não chegar. Nesse caso, esta tem de ser completada pelo amor, "o qual na expressão da "Gaudium et Spes" do Concílio Vaticano II, vai além do que a justiça consegue alcançar» $\left(\mathrm{n}^{\circ}\right.$ 78).

Ora quem sabe completar a justiça pela prática do amor é capaz de percorrer os caminhos exigentes da não violência para construir a paz no mundo e entre todos os homens. Diz a "Gaudium et Spes" sobre a não violência: "Não podemos deixar de louvar aqueles que, renunciando à violência na reivindicação dos seus próprios direitos, recorrem a meios de 
defesa que estão também ao alcance dos mais fracos, sempre que isso se possa fazer sem lesar os direitos e obrigações de outros e da comunidade" $\left(n^{\circ} 78\right)$

\section{CONCLUSÃO}

O desenvolvimento é o novo nome da paz.

Esta afirmação em título na conclusão da "Populorum Progressio" fundamentada na "Gaudium et Spes" do Concílio Vaticano II convida-nos a repensar sempre criticamente os modelos de desenvolvimento que nos são propostos.

O desenvolvimento que nos serve tem de ser uma realidade aberta e não fechada, de acordo com a abertura estruturante do ser humano na sua caminhada da realização pessoal, social e mesmo mundana. O desenvolvimento autenticamente humano ou integral pressupõe o humanismo total, que por sua vez obriga a reconhecer e a levar a sério todas as dimensões do ser humano, incluindo a dimensão transcendente e sobrenatural. Com base neste pressuposto, a "Populorum Progressio" assume uma atitude fortemente crítica face ao moderno secularismo, quando diz: "O homem pode organizar a terra sem Deus, mas sem Deus só a pode organizar contra o homem. Humanismo exclusivo (radical) é desumano" ( $\left.n^{\circ} 42\right)$. Os factos só vieram, infelizmente, confirmar esta tese.

Por sua vez, a paz verdadeira nunca pode ser a paz imposta pelas armas, como não pode ser a paz dos sem vida nos cemitérios. Longe de ser uma atitude negativa ou mesmo defensiva, a paz verdadeira será sempre a atitude positiva de quem, em diálogo e colaboração com os outros, interpreta e vive responsavelmente os dinamismos da ordem introduzida pelo criador no mundo, na história e nos seres humanos enquanto tais. 